
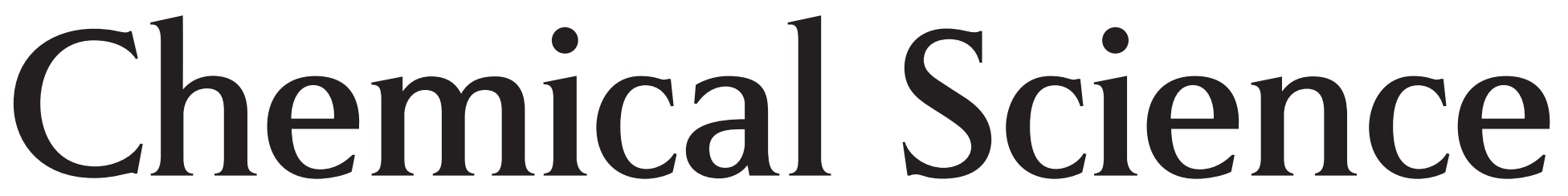


\title{
Methane activation and exchange by titanium-carbon multiple bonds $\dagger$
}

\author{
Jaime A. Flores, ${ }^{a}$ Vincent N. Cavaliere, ${ }^{a}$ Dominik Buck, ${ }^{a}$ Balázs Pintér, ${ }^{a}$ George Chen, ${ }^{b}$ Marco G. Crestani, ${ }^{a}$ \\ Mu-Hyun Baik $* a$ and Daniel J. Mindiola $* a$
}

\author{
Received 9th March 2011, Accepted 28th April 2011 \\ DOI: 10.1039/c1sc00138h
}

\begin{abstract}
We demonstrate that a titanium-carbon multiple bond, specifically an alkylidyne ligand in the transient complex, $(\mathrm{PNP}) \mathrm{Ti} \equiv \mathrm{C}^{t} \mathrm{Bu}(\mathrm{A})\left(\mathrm{PNP}^{-}=\mathrm{N}\left[2-\mathrm{P}\left(\mathrm{CHMe}_{2}\right)_{2}-4 \text {-methylphenyl }\right]_{2}\right)$, can cleanly activate methane at room temperature with moderately elevated pressures to form (PNP)Ti $=\mathrm{CH}^{t} \mathrm{Bu}\left(\mathrm{CH}_{3}\right)$. Isotopic labeling and theoretical studies suggest that the alkylidene and methyl hydrogens exchange, either via tautomerization invoking a methylidene complex, $(\mathrm{PNP}) \mathrm{Ti}=\mathrm{CH}_{2}\left(\mathrm{CH}_{2}{ }^{\mathrm{B} u}\right)$, or by forming the methane adduct $(\mathrm{PNP}) \mathrm{Ti} \equiv \mathrm{C}^{t} \mathrm{Bu}\left(\mathrm{CH}_{4}\right)$. The thermal, fluxional and chemical behavior of $(\mathrm{PNP}) \mathrm{Ti}=\mathrm{CH}^{\prime} \mathrm{Bu}\left(\mathrm{CH}_{3}\right)$ is also presented in this study.
\end{abstract}

\section{Introduction}

Methane is the most abundant and least reactive of all paraffins, accounting for $70-90 \%$ of the vast reserves of natural gas accessible today. With the feedstock of petroleum rapidly dwindling, and the ever-increasing need for energy, a multifaceted approach to the use of cleaner, cheaper, domestic energy sources is required. The exploitation of the intrinsic energy stored in the $\mathrm{C}-\mathrm{H}$ bonds of methane, a potent greenhouse gas itself, via controlled activation and functionalization, ${ }^{1}$ represents a quintessential challenge. However, methane's low binding affinity for potential $\mathrm{C}-\mathrm{H}$ activation and functionalization catalysts in addition to its low reactivity render this substrate untameable for these goals. One strategy towards employing this $\mathrm{C}_{1}$ feedstock is alkane metathesis, ${ }^{2-5}$ where long alkane skeletons are constructed by the combination of $\mathrm{C}-\mathrm{H}$ bond breaking and $\mathrm{C}-\mathrm{C}$ bond forming steps. Metal-carbon multiple bonds are thought to play a critical role as reactive intermediates in the aforementioned reactions promoted by solid-state supported Ta, Mo, and $\mathrm{W}$ hydrides, ${ }^{2-6}$ and are certainly involved in recently discovered homogeneous tandem alkane dehydrogenation/olefin metathesis catalytic systems. ${ }^{6}$ Although metal centers carrying methyl ligands have been speculated upon for alkane metathesis catalysts, ${ }^{5}$ examples of well-defined homogeneous systems that can dehydrogenate methane ${ }^{7}$ in a mechanistically clean fashion remain elusive. ${ }^{4,8}$ It is now well established that transition metal alkylidene $e^{9}$ and alkylidyne ${ }^{10}$ complexes can activate aromatic and some aliphatic $\mathrm{C}-\mathrm{H}$ bonds in an intermolecular manner.

${ }^{a}$ Department of Chemistry, E Kirkwood Rd, Bloomington, Indiana, 47405, USA. E-mail: mindiola@indiana.edu; Fax: +1 812855 8300; Tel: +1 812 8552399

${ }^{b}$ Division of Chemistry and Chemical Engineering, California Institute of Technology, E California Blvd, Pasadena, California, 91125, USA

$\dagger$ Electronic supplementary information (ESI) available: Experimental procedures, spectroscopic data for all new compounds, kinetics data, and theoretical protocols. See DOI: 10.1039/c1sc00138h
Surprisingly, there are no examples of well-defined complexes containing metal-carbon multiple bonds capable of activating the parent alkane, methane, even though metal-imides $(\mathrm{M}=\mathrm{NR}),{ }^{11}$ which can be seen as closely related analogues, are known to show remarkable reactivity towards methane.

In this study we demonstrate that the transient titanium alkylidyne, $(\mathrm{PNP}) \mathrm{Ti} \equiv \mathrm{C}^{\prime} \mathrm{Bu}\left(\mathrm{PNP}^{-}=\mathrm{N}\left[2-\mathrm{P}\left(\mathrm{CHMe}_{2}\right)_{2}-4\right.\right.$-methylphenyl $\left.]_{2}\right),{ }^{10}$ can activate methane at room temperature to form (PNP) $\mathrm{Ti}=\mathrm{CH}^{t} \mathrm{Bu}\left(\mathrm{CH}_{3}\right)$. Isotopic labelling studies revealed that the Ti-methyl hydrogens in $(\mathrm{PNP}) \mathrm{Ti}=\mathrm{CH}^{t} \mathrm{Bu}\left(\mathrm{CH}_{3}\right)$ exchange with the alkylidene hydrogen thereby suggesting either a tautomerization and/or abstraction pathway to be operative. Theoretical studies also support either pathway with the abstraction route having a slightly lower barrier.

\section{Results and discussion}

\section{Methane activation by a titanium neopentylidyne}

Previously, we discovered that the alkylidyne precursor (PNP) $\mathrm{Ti}=\mathrm{CH}^{t} \mathrm{Bu}\left(\mathrm{CH}_{2}{ }^{t} \mathrm{Bu}\right)$ (1) can eliminate $\mathrm{CH}_{3}{ }^{t} \mathrm{Bu}$ to furnish the transient species $(\mathrm{PNP}) \mathrm{Ti} \equiv \mathrm{C}^{\prime} \mathrm{Bu}(\mathbf{A})$, which can activate benzene to afford (PNP) $\mathrm{Ti}=\mathrm{CH}^{t} \mathrm{Bu}\left(\mathrm{C}_{6} \mathrm{H}_{5}\right)$ (2), quantitatively (Scheme 1). ${ }^{10 a, b}$ In cyclohexane (or $\mathrm{C}_{6} \mathrm{D}_{12}$ ) at $31^{\circ} \mathrm{C}$, complex 1 decays with a pseudo first-order rate constant $k=5.86 \times 10^{-5} \mathrm{~s}^{-1}$ to myriad products which include $\mathrm{CH}_{3}{ }^{t} \mathrm{Bu}$ and cyclohexene (inferred by ${ }^{1} \mathrm{H}$ NMR spectroscopy and GC-MS of the volatiles). ${ }^{12,13}$ The same complicated mixture of products is formed when $(\mathrm{PNP}) \mathrm{Ti}=\mathrm{CH}^{t} \mathrm{Bu}(\mathrm{OTf})(3)$ is treated with $\mathrm{Li}\left(\right.$ cyclo- $\left.\mathrm{C}_{6} \mathrm{H}_{11}\right)$, therefore suggesting that the putative species $(\mathrm{PNP}) \mathrm{Ti}=\mathrm{CH}^{t} \mathrm{Bu}$ (cyclo- $\mathrm{C}_{6} \mathrm{H}_{11}$ ), if formed, is unstable under these conditions. Furthermore, at $27{ }^{\circ} \mathrm{C}$ complex 1 decays with a $t_{1 / 2}$ of $3.1 \mathrm{~h}$, independent of whether the solvent is benzene, cyclohexane, hydrofluoroarenes or hydrofluoroalkanes. ${ }^{10}$ These results demonstrated the versatility of $\mathbf{A}$ as a key intermediate, and pointed at its potential for activating $\mathrm{C}-\mathrm{H}$ bonds. Quantum 


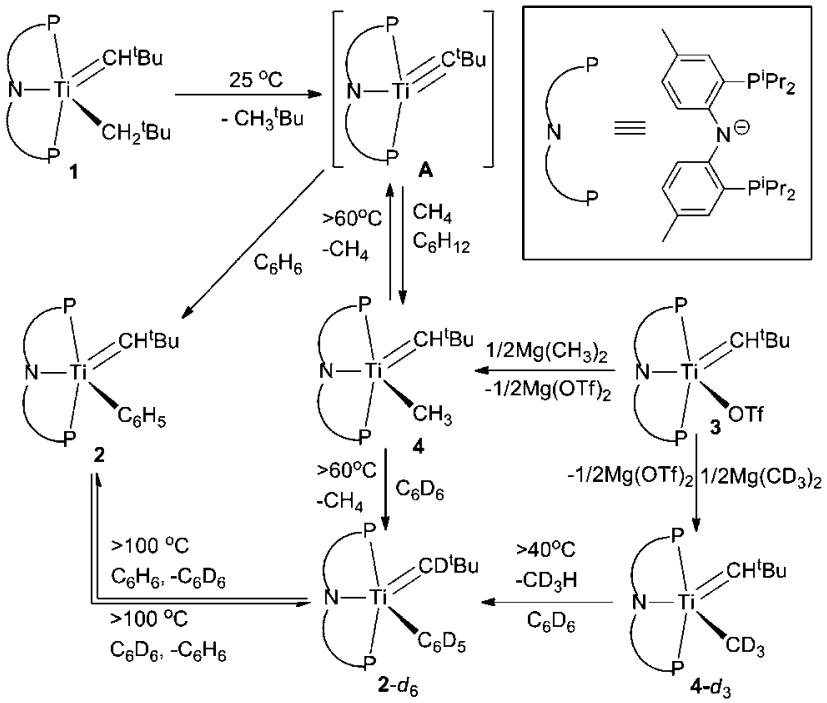

Scheme 1 Methane activation by complex $\mathbf{1}$ via $\mathbf{A}$ to form $\mathbf{4}$ as well as other reactivity of $\mathbf{1}$ and thermal stability of $\mathbf{4}$ and $\mathbf{4}-d_{3}$.

chemical computer simulations estimated transient $\mathbf{A}$ to be higher in energy than the precursor $\mathbf{1}$ by $\sim 5 \mathrm{kcal} \mathrm{mol}^{-10}$ and suggested that methane should react with this intermediate under mild conditions. Thus, we hypothesized that methane would be a suitable substrate for reaction with complex $\mathbf{A}$.

Exposure of a solution of 1 to $\mathrm{CH}_{4}$ at a pressure of 310 psi at $31{ }^{\circ} \mathrm{C}$ afforded the $\mathrm{C}-\mathrm{H}$ activation product $(\mathrm{PNP}) \mathrm{Ti}=\mathrm{CH}^{t} \mathrm{Bu}\left(\mathrm{CH}_{3}\right)(4)$ in $54 \%$ conversion (based on ${ }^{31} \mathrm{P}$ NMR spectra) after $12 \mathrm{~h}$ with $k_{\text {avg }}=$ 5.3(5) $\times 10^{-5} \mathrm{~s}^{-1}$ over five independent runs (Fig. 1, Graph A). A similar reaction was observed at $725 \mathrm{psi}$ of $\mathrm{CH}_{4}\left(k=7.2 \times 10^{-5} \mathrm{~s}^{-1}\right.$, $50-60 \%$ conversion). Interestingly, conversion of 1 to 4 in $95 \%$ yield over $12 \mathrm{~h}$ could be achieved by increasing the methane pressure to 1150 psi at $31^{\circ} \mathrm{C}$ with $k=7.9 \times 10^{-5} \mathrm{~s}^{-1}$. Legzdins observed similar reactivity of the transient butadiene complex, $\mathrm{Cp} * \mathrm{~W}(\mathrm{NO})\left(\eta^{2}-\mathrm{CH}_{2}=\mathrm{CHCH}=\mathrm{CH}_{2}\right)$ with methane at moderately elevated pressures $(1025 \mathrm{psi}) .{ }^{14}$ Therefore, varying the pressure of methane does not inflict any significant change on the pseudo-first order rate of decay of $\mathbf{1}$ (Fig. 1, Graph B), but it affects the yield of 4 . Deuteration studies with $\mathrm{CD}_{4}$ at 260 psi verified the formation of the isotopologue, $(\mathrm{PNP}) \mathrm{Ti}=\mathrm{CD}^{\prime} \mathrm{Bu}\left(\mathrm{CD}_{3}\right)(4)-d_{4}$, reaffirming that $\mathrm{C}-\mathrm{H}$ activation most likely proceeds via $1,2-\mathrm{CH}$ bond addition across the alkylidyne ligand of $\mathbf{A}$. Moreover, when $\mathrm{CD}_{4}$ was used, the average rate did not notably deviate from that observed for the activation of $\mathrm{CH}_{4}$ under similar conditions $\left(k_{\mathrm{H}} / k_{\mathrm{D}}=1.2(1), 31^{\circ} \mathrm{C}\right.$, Graph A in Fig. 1), thus reasserting that the slow step in the $\mathbf{1} \rightarrow \mathbf{4}$ transformation precedes methane activation.

From our previous experience in $\mathrm{C}-\mathrm{H}$ activation, we anticipated that deuterating all $\alpha$-positions in $\mathbf{1}$, to form $(\mathrm{PNP}) \mathrm{Ti}=\mathrm{CD}^{t} \mathrm{Bu}\left(\mathrm{CD}_{2}{ }^{t} \mathrm{Bu}\right)\left(\mathbf{1}-d_{3}\right)$, should give rise to a KIE of $\sim 4$ at $40{ }^{\circ} \mathrm{C}$ since $\alpha$-hydrogen abstraction is expected to be overall rate-determining. ${ }^{10,12,15}$ To study the $\mathrm{C}-\mathrm{H}$ activation step in more detail we prepared the $d_{1}$ mixture of isotopomers, (PNP) $\mathrm{Ti}=\mathrm{CH}^{t} \mathrm{Bu}\left(\mathrm{CHD}^{t} \mathrm{Bu}\right) /(\mathrm{PNP}) \mathrm{Ti}=\mathrm{CD}^{\prime} \mathrm{Bu}\left(\mathrm{CH}_{2}{ }^{t} \mathrm{Bu}\right) \quad(\mathbf{1})-d_{1}$ by treating 3- $d_{1}$ with $\mathrm{LiCH}_{2}{ }^{t} \mathrm{Bu},{ }^{10}$ so as to slow down the rate of decay of the precursor complex and expedite data collection at moderate pressures of $\mathrm{CH}_{4}$. When $\mathbf{1}-d_{1}$ was exposed to $310 \mathrm{psi}$ of $\mathrm{CH}_{4}$ pressure, $\mathrm{KIE}=2.3$ at $31{ }^{\circ} \mathrm{C}$ was observed (Fig. 1, Graph A), confirming that the formation of $\mathbf{A}$, and not the intermolecular $\mathrm{C}-\mathrm{H}$ bond activation step of methane, is ratedetermining.

\section{Characterization and thermal stability of complex 4}

Unlike most organometallic systems that activate methane under mild conditions $\left(<50{ }^{\circ} \mathrm{C}\right),{ }^{1 a, 7 b-c, 11,14,16}$ complex 4 is remarkably stable in $\mathrm{C}_{6} \mathrm{D}_{6}$ at room temperature (rt) with only $<5 \%$ conversion to $\mathbf{2}-d_{6}$ after six weeks. ${ }^{13}$ However, complex 4 extrudes methane in $\mathrm{C}_{6} \mathrm{D}_{6}$ at $60{ }^{\circ} \mathrm{C}$ to form $2-d_{6}$, but does so slowly with a $t_{1 / 2}$ of $62.4 \mathrm{~h}$ and $k=3.09 \times 10^{-6} \mathrm{~s}^{-1}$. Exploring this reaction over the temperature range $60-90^{\circ} \mathrm{C}$ allowed for the extraction of activation parameters $\Delta H^{\ddagger}=29(3) \mathrm{kcal} \mathrm{mol}^{-1}$ and $\Delta S^{\ddagger}=0.0$ (5) eu (Fig. 2). ${ }^{13}$ These parameters suggest an overall similar mechanism for the conversion of $\mathbf{1}$ to $\mathbf{2}-d_{6}$ but invoke a higher
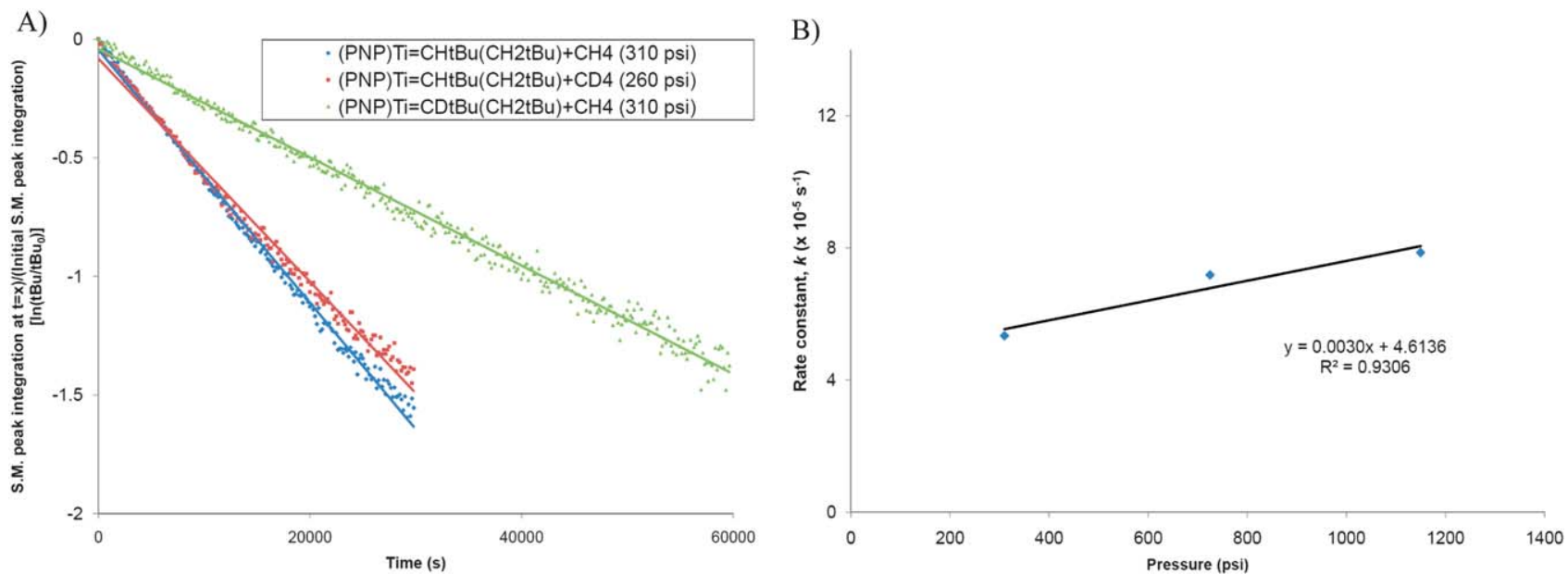

Fig. 1 Kinetic studies for the conversion of $\mathbf{1}$ to $\mathbf{4}$ under various pressures of methane. Graph A depicts the pseudo-first order decay of $\mathbf{1}$ under 310 psi of $\mathrm{CH}_{4}$ and $260 \mathrm{psi} \mathrm{CD}_{4}$ as well as decay of $\mathbf{1}-d_{1}$ under 310 psi of $\mathrm{CH}_{4}$. Graph B shows the dependence of rate on pressure for the conversion of $\mathbf{1}$ to 4 at 310,725 , and 1150 psi of $\mathrm{CH}_{4}$. 


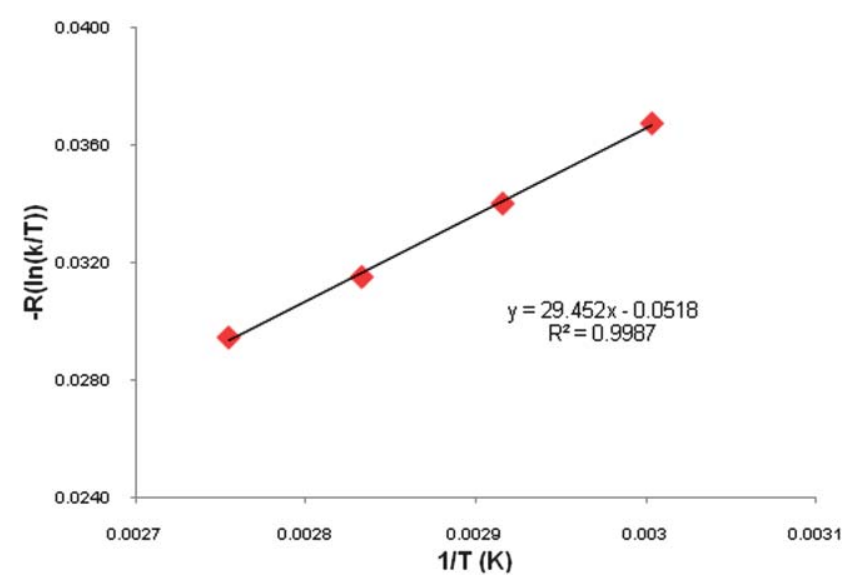

Fig. 2 Eyring plot for the conversion of 4 to $2-d_{6}$ in $\mathrm{C}_{6} \mathrm{D}_{6}$ along with a table of rate constants.

barrier for the formation of $\mathbf{A}\left(\Delta G^{\sharp} \sim 28 \mathrm{kcal} \mathrm{mol}^{-1}\right)$ given the thermal stability of $\mathbf{4}$ with respect to $\mathbf{1}$.

To confirm our spectroscopic characterization of $\mathbf{4}$, we prepared it independently by salt metathesis of $\mathbf{3}$ with 0.5 equivalents of freshly prepared $\mathrm{Mg}\left(\mathrm{CH}_{3}\right)_{2}\left(\mathrm{OEt}_{2}\right)_{x}$ in diethylether, in $97 \%$ isolated yield. Diagnostic features of $\mathbf{4}$ include an alkylidene and methyl resonance at 8.30 and $0.81 \mathrm{ppm}$, respectively, established by the ${ }^{1} \mathrm{H}$ NMR spectrum collected at rt. The methyl protons $(0.81 \mathrm{ppm})$ exhibit a triplet $\left({ }^{3} J_{\mathrm{HP}}=3 \mathrm{~Hz}\right)$ due to coupling with the transoid phosphine groups. The phosphine resonances in complex $\mathbf{4}$ are significantly shifted (32.00 and $21.69 \mathrm{ppm},{ }^{2} J_{\mathrm{PP}}=43.9 \mathrm{~Hz}$ ) from those observed in 3 or the degenerate alkylidene-alkyl 1 allowing for convenient monitoring of the reaction mixture by ${ }^{31} \mathrm{P}$ NMR spectroscopy. By ${ }^{13} \mathrm{C}$ NMR spectroscopy the alkylidene carbon resonance in $\mathbf{4}$ is extremely broad at rt. Thus, we conducted variable temperature multinuclear NMR experiments to resolve the ${ }^{13} \mathrm{C}$ NMR spectrum of 4. Accordingly, the ${ }^{13} \mathrm{C}$ NMR spectrum of 4 at $50{ }^{\circ} \mathrm{C}$ displays a more intense signal at $286 \mathrm{ppm}(387 \mathrm{~Hz})$ while lowering the temperature of the solution to $-80^{\circ} \mathrm{C}$ fully resolved this resonance into two distinct peaks, suggesting the presence of two species. ${ }^{13}$ By applying a combination of HMQC, $45^{\circ}$ DEPT, and ${ }^{1} \mathrm{H}$-coupled ${ }^{13} \mathrm{C}$ NMR experiments, the alkylidene resonances observed in the ${ }^{13} \mathrm{C}$ NMR spectrum collected at $-80^{\circ} \mathrm{C}$ (299.2 ppm, doublet, ${ }^{1} J_{\mathrm{CH}}=96.3 \mathrm{~Hz}$ and $268.8 \mathrm{ppm}$, doublet, $J_{\mathrm{CH}}=76.2 \mathrm{~Hz}$ ), could be readily correlated to the downfield ${ }^{1} \mathrm{H}$ NMR resonances at 8.90 and $7.90 \mathrm{ppm}$, respectively. As a result, we propose that complex $\mathbf{4}$ exists as a mixture of alkylidene isomers (also referred to as rotamers), 4-anti and 4-syn (Scheme 2), ${ }^{17}$ which isomerize rapidly on the NMR time scale with a low barrier of $10.9 \mathrm{kcal} \mathrm{mol}^{-1}$ at $-28.9^{\circ} \mathrm{C}$. Variable temperature ${ }^{31} \mathrm{P}$ NMR spectroscopy also corroborate the formation of two isomers of $\mathbf{4}$. The ${ }^{31} \mathrm{P}$ NMR spectrum of $\mathbf{4}$ at $-28.9^{\circ} \mathrm{C}$ revealed coalescence of the two doublets observed at rt, while further cooling of the NMR solution to $-60{ }^{\circ} \mathrm{C}$ resolved the broad resonances into two $\mathrm{AB}$ couplets, consistent with two distinct $C_{1}$ symmetric titanium complexes in approximately $3: 2$ ratio. Increasing the temperature to rt regenerated the original "averaged" $\mathrm{AB}$ set, indicating rapid chemical $\mathrm{Ti}=\mathrm{C}$ bond rotation with respect to the NMR time scale. Therefore, complex $\mathbf{4}$, which

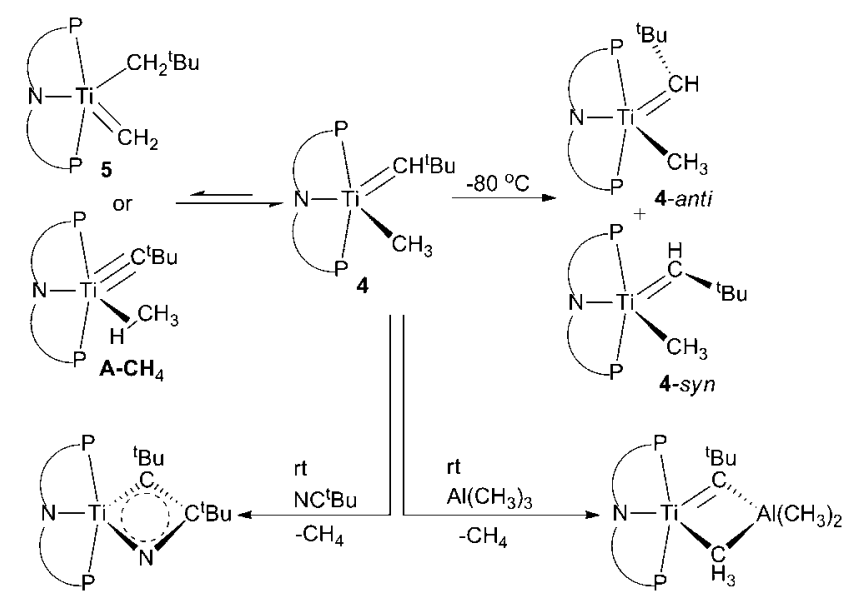

Scheme 2 Isomers 4-syn and 4-anti detected at low temperature, tautomerization to the methane adduct $\mathbf{A}-\mathbf{C H}_{\mathbf{4}}$, or methylidene complex $\mathbf{5}$, and reactivity showing $\mathbf{4}$ and not $\mathbf{5}$ is the resting tautomeric form.

can be derived from methane activation, exist as a mixture of alkylidene rotamers at $\mathrm{rt}$.

We have found that complex $\mathbf{4}$ behaves like an alkylidyne synthon analogous to $\mathbf{1}$. The treatment of $\mathbf{4}$ with $\mathrm{Al}\left(\mathrm{CH}_{3}\right)_{3}$ generated the known neopentylidyne-zwitterion (PNP)Ti $\left(\mu_{2}-\mathrm{C}^{t} \mathrm{Bu}\right)\left(\mu_{2}-\mathrm{CH}_{3}\right)\left(\mathrm{AlMe}_{2}\right)^{18}$ concurrent with $\mathrm{CH}_{4}$ elimination. Likewise, the neopentylidyne functionality can also be trapped with $\mathrm{NC}^{t} \mathrm{Bu}$ to render the azametallacyclobutadiene complex (PNP)Ti( $\left.\mathrm{C}^{t} \mathrm{BuC} \mathrm{CuN}^{\prime}\right)^{19}$ along with release of $\mathrm{CH}_{4}$ (Scheme 2). Both complexes were generated quantitatively as established by ${ }^{31} \mathrm{P}$ NMR spectroscopy as well as isolated in yields exceeding $70 \%$ without evidence of formation of another species.

\section{Proton exchange in complex 4}

In order to elucidate the dynamics of the alkyl and alkylidene ligands in $\mathbf{4}$, isotopic labelling experiments were performed by independently preparing the isotopologues $(\mathrm{PNP}) \mathrm{Ti}=\mathrm{CD}^{t} \mathrm{Bu}\left(\mathrm{CH}_{3}\right)(\mathbf{4})-d_{1},(\mathrm{PNP}) \mathrm{Ti}=\mathrm{CH}^{t} \mathrm{Bu}\left(\mathrm{CD}_{3}\right) \quad(\mathbf{4})-d_{3}$, and $(\mathrm{PNP}) \mathrm{Ti}=\mathrm{CD}^{\prime} \mathrm{Bu}\left(\mathrm{CD}_{3}\right)(\mathbf{4})-d_{4} \cdot{ }^{13}$ Complex 4- $d_{1}$ eliminates $\mathrm{CDH}_{3}$ more slowly than 4 extrudes $\mathrm{CH}_{4}$ in a $\mathrm{C}_{6} \mathrm{D}_{6}$ solution $\left(\mathrm{KIE}=1.79,80{ }^{\circ} \mathrm{C}\right)$ to cleanly produce compound $\mathbf{2}-d_{6}$ (Scheme 1). Since 4- $d_{1}$ extrudes $\mathrm{CDH}_{3}$ slowly at temperatures exceeding $60{ }^{\circ} \mathrm{C}$, it provided us with a window of $\Delta T \sim 33^{\circ} \mathrm{C}$ to examine if such $d$-exchange is possible at the $\alpha$-carbons. Mild thermolysis of 4- $d_{1}$ in $\mathrm{C}_{6} \mathrm{D}_{6}$ over 4 days at $40{ }^{\circ} \mathrm{C}$ slowly gave rise to proton incorporation at the neopentylidene $\alpha$-C to form the isotopomer $(\mathrm{PNP}) \mathrm{Ti}=\mathrm{CH}^{t} \mathrm{Bu}\left(\mathrm{CDH}_{2}\right)$. This suggests that the $\alpha$-hydrogens of the methyl and alkylidene ligands in $\mathbf{4}$ must be exchanging. ${ }^{13,20}$ Fig. 3 depicts stacked ${ }^{1} \mathrm{H}$ NMR spectra of the expanded aryl region of 4- $d_{1}$ in $\mathrm{C}_{6} \mathrm{D}_{6}\left(80^{\circ} \mathrm{C}\right)$, which highlights proton-inclusion at the alkylidene position. In addition, the slow background reaction involving elimination of $\mathrm{CDH}_{3}$ concurrent with formation of 2- $d_{6}$ at the expense of the decay of 4- $d_{1}$ is observed. The exchange of $\mathbf{4}-d_{1}$ to $(\mathrm{PNP}) \mathrm{Ti}=\mathrm{CH}^{t} \mathrm{Bu}\left(\mathrm{CDH}_{2}\right)$ is not only slow but reversible since we also observe deuterium exchange in the isotopologue 4- $d_{3}$ after 4 days at $40{ }^{\circ} \mathrm{C}$ in $\mathrm{C}_{6} \mathrm{D}_{6}-$ in addition to formation of some $2-d_{6}$ and $\mathrm{CHD}_{3}$ by ${ }^{1} \mathrm{H}$ and ${ }^{2} \mathrm{D}$ NMR spectroscopy. ${ }^{13}$ Inadvertently, the exchange in $4-d_{3}$ in 


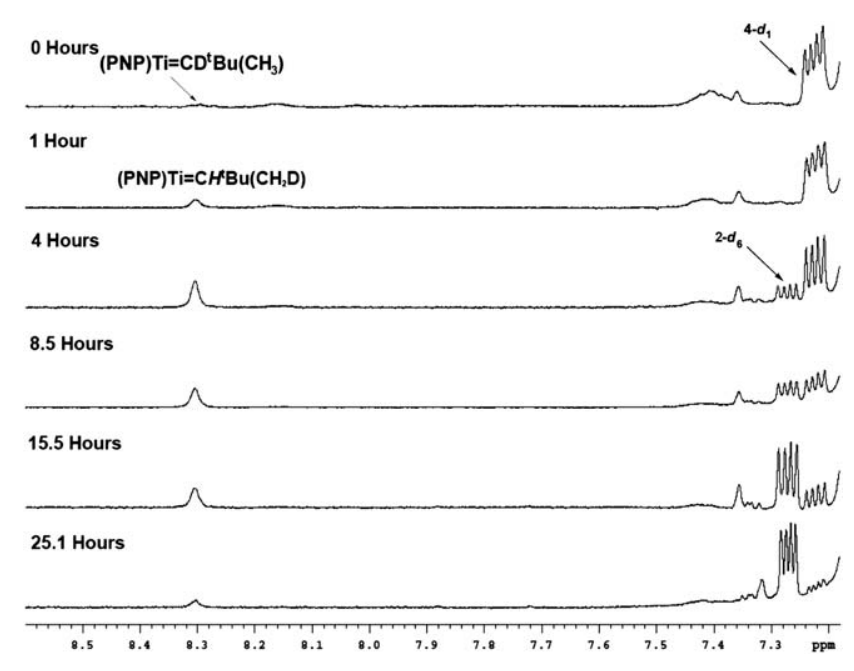

Fig. $3{ }^{1} \mathrm{H}$ NMR spectra at low field region for the thermolysis of $(\mathrm{PNP}) \mathrm{Ti}=\mathrm{CD}^{\prime} \mathrm{Bu}\left(\mathrm{CH}_{3}\right)$ in $\mathrm{C}_{6} \mathrm{D}_{6}$ at $80{ }^{\circ} \mathrm{C}$.

$\mathrm{C}_{6} \mathrm{D}_{6}$ is slow and thus overshadowed by $\alpha$-hydrogen abstraction $\left(\mathrm{CHD}_{3}\right.$ elimination) given that the rate of conversion to $2-d_{6}$ at $80{ }^{\circ} \mathrm{C}$ is very close to the rate of conversion of $\mathbf{4}$ to $\mathbf{2}-d_{6}$ $(\mathrm{KIE}=1.01)$.

To corroborate that exchange does take place in $\mathbf{4}$, the rate of decay of $\mathbf{4}-d_{4}$ to $\mathbf{2}-d_{6}$ in $\mathrm{C}_{6} \mathrm{D}_{6}$ was also measured. The KIE is higher than that observed for $4-d_{1}\left(\mathrm{KIE}=2.06,80^{\circ} \mathrm{C}\right)$. The difference in rate constants between 4- $d_{1}$ and 4- $d_{4}$ must arise from hydrogen exchange (vide infra). As a result of our studies, we propose the exchange phenomenon in complex 4 to occur via a tautomerization, meaning formation of a methylidene complex (PNP) Ti $=\mathrm{CH}_{2}\left(\mathrm{CH}_{2}{ }^{t} \mathrm{Bu}\right)(5)$, or by abstraction/addition via the methane adduct (PNP) $\mathrm{Ti} \equiv \mathrm{C}^{t} \mathrm{Bu}\left(\mathrm{CH}_{4}\right), \mathbf{A}-\mathbf{C H}_{\mathbf{4}}$ (Scheme 2). Our previous work established that the $\alpha$-hydrogens in $(\mathrm{PNP}) \mathrm{Ti}=\mathrm{CH}^{t} \mathrm{Bu}\left(\mathrm{CD}_{2}{ }^{t} \mathrm{Bu}\right)$ can rapidly exchange at room temperature to a mixture of isotopomers $1-d_{2}(1: 2$ ratio), so the proposed exchange observed here is not completely unexpected. ${ }^{10,12}$

\section{Theoretical studies of the proton exchange in complex 4}

Density functional theoretical analysis suggests that the activation energies of the $\alpha$-hydrogen abstraction and tautomerization routes are energetically similar, with the former being 33 and the latter $36 \mathrm{kcal} \mathrm{mol}^{-1}$. Fig. 4 depicts these two most probable pathways of reaction for complex $\mathbf{4}$, illustrating that $\mathbf{4}$ is significantly lower in solution-phase free energy than its tautomeric methylidene complex $\mathbf{5}$, which lies about $8 \mathrm{kcal} \mathrm{mol}^{-1}$ higher in energy than $\mathbf{4}$, but $10 \mathrm{kcal} \mathrm{mol}^{-1}$ below the transient alkylidyne $\mathrm{A}$ and $18 \mathrm{kcal} \mathrm{mol}^{-1}$ below $\mathbf{A}-\mathbf{C H}_{\mathbf{4}}$. In addition to paths a and $\mathrm{b}$ having similar rate determining barriers, $\mathbf{4}-\mathbf{T S}_{\mathbf{a}}$ and $\mathbf{4}-\mathbf{T S}_{\mathbf{b}}$, Fig. 4 more clearly depicts how isotopologues $\mathbf{4}-d_{1}$ and $\mathbf{4}-d_{3}$ increase the energies of $\mathbf{4}-\mathbf{T S}_{\mathbf{b}}$ and $\mathbf{4}-\mathbf{T S}_{\mathbf{a}}$, respectively.

At present, we propose part of the difference in energy between 4 and 5 to be imposed by an $\alpha$-agostic interaction present in the neopentylidene (and absent in the methylidene). This type of interaction can account for 1-10 $\mathrm{kcal} \mathrm{mol}^{-1}$, which could explain a difference in energy of $8 \mathrm{kcal} \mathrm{mol}^{-1}$. In fact, the computed Ti$\mathrm{C}-\mathrm{H}$ angles of $118.5^{\circ}$ and $129.7^{\circ}$ and $\mathrm{H}-\mathrm{C}-\mathrm{H}$ angle of $111.8^{\circ}$ in $\mathbf{5}$
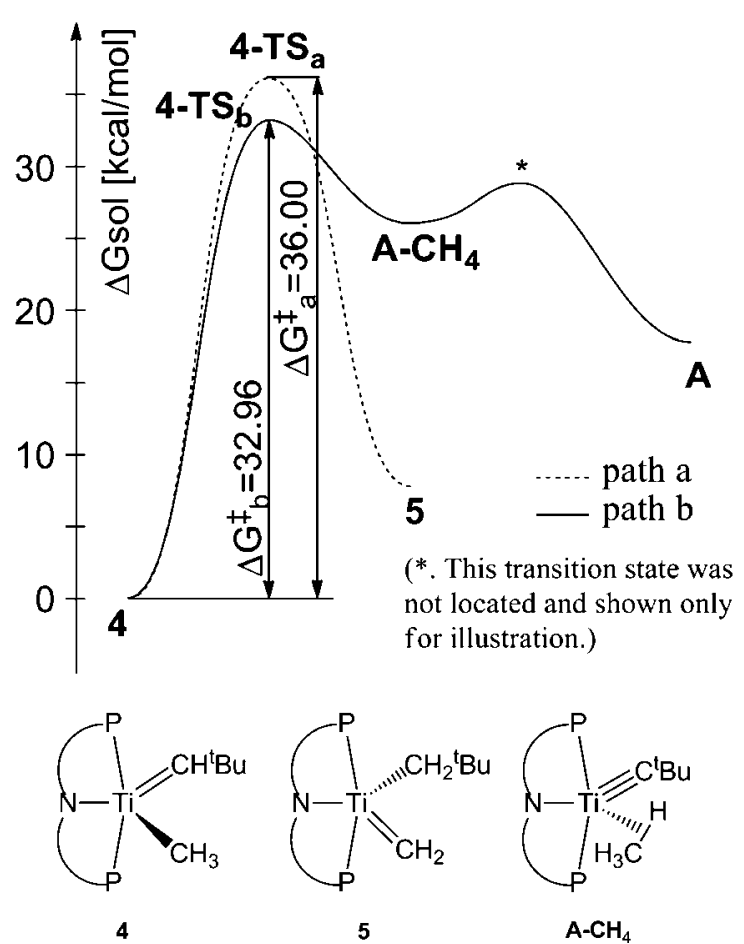

[0.00]

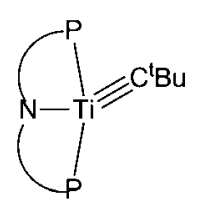

5

A- $\mathrm{CH}_{4}$

[26.04]
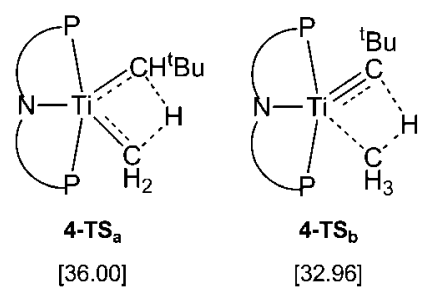

[17.66]

[36.00]

[32.96]

Fig. 4 Computed reaction profile illustrating the competition between methane extrusion (path b) and tautomerization (path a) in complex 4. Values shown in brackets are computed solution-state free energies $\left(\Delta G_{\mathrm{sol}}\right)$ in $\mathrm{kcal} \mathrm{mol}^{-1}$.

indicate an extremely weak $\alpha$-agostic interaction of the methylidene with the Ti(Iv) center. These structural alterations obtained for the optimized geometry computed for $\mathbf{5}$, are much less pronounced than those observed in stable tungsten and molybdenum methylidene complexes, ${ }^{21}$ in which more acute $\mathrm{M}-\mathrm{C}-\mathrm{H}$ angles are observed $\left(105-107^{\circ}\right)$. Thus, the data presented here suggests that the $\alpha$-agostic bond in the titanium-methylidene
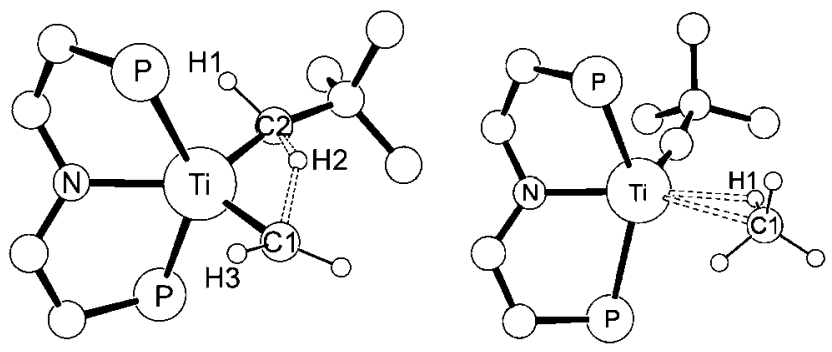

Fig. 5 Computed structures of $\mathbf{4}-\mathbf{T S}_{\mathbf{a}}$ (left) and intermediate $\mathbf{A}-\mathbf{C H}_{\mathbf{4}}$. Only the most important atoms are shown for clarity (PNP ligand peripherals are omitted). 
complex 5 might be playing a minor role. Presently, we do not know what other factors could be accounting for this difference in energy. To better understand why $\mathbf{5}$ is energetically difficult to generate, we investigated 4-TS $\mathbf{a}$. Fig. 5 shows the computed structure of $\mathbf{4}-\mathbf{T S}_{\mathbf{a}}$, which adopts a trigonal-bipyramidal geometry with the migrating hydrogen $\mathrm{H} 1$ being located halfway between the donor carbon $\mathrm{C} 1$ and the acceptor carbon $\mathrm{C} 2$ with $\mathrm{C}-\mathrm{H}$ distances of 1.51 and $1.50 \AA$, respectively. Interestingly, in 4-TS $\mathbf{a}$ both $\mathrm{C} 1-\mathrm{H} 3$ and $\mathrm{C} 2-\mathrm{H} 1$ bonds display an $\alpha$-agostic interaction with the titanium center $\left(d_{\mathrm{Ti}-\mathrm{H} 3}=2.21, \angle_{\mathrm{Ti}-\mathrm{Cl}-\mathrm{H} 3}=\right.$ $\left.90.6^{\circ}, d_{\mathrm{Ti}-\mathrm{H} 1}=2.09 \AA, \angle_{\mathrm{Ti}-\mathrm{Cl}-\mathrm{H} 3}=83.6^{\circ}\right)$ lowering the energy of this transition state. ${ }^{22}$ This step can be described as a metal mediated $\alpha$-hydrogen migration as indicated by the relatively short Ti-H2 distance of $1.72 \AA$, a Wiberg bond order of 0.18 and Natural Population Analysis (NPA) electron density of 0.71 at $\mathrm{H} 2$ in the transition state.

As shown in Fig. 4, a conceivable pathway for observed hydrogen exchange in $\mathbf{4}$ is by way of the alkane sigmacomplex, $\mathbf{A}-\mathbf{C H}_{\mathbf{4}}$. In contrast to the relatively long-lived $\left[\left(2,6-\left({ }^{t} \mathrm{Bu}_{2} \mathrm{PO}\right)_{2} \mathrm{C}_{5} \mathrm{H}_{3} \mathrm{~N}\right) \mathrm{Rh}\left(\mathrm{CH}_{4}\right)\right]^{+} \quad \sigma$-methane complex, ${ }^{23}$ $\mathbf{B}-\mathbf{C H}_{4}$, which was recently characterized in solution by Brookhart and Goldberg, $\mathbf{A}-\mathbf{C H}_{\mathbf{4}}$ must be an extremely labile $\sigma$-adduct lying 26 and $10 \mathrm{kcal} \mathrm{mol}^{-1}$ higher in energy than complex $\mathbf{4}$ and the separated products, respectively. ${ }^{23}$ In $\mathbf{A}-\mathbf{C H}_{\mathbf{4}}$ methane occupies one of the equatorial positions of the approximately trigonal-bipyramidal geometry and binds in an $\eta^{2}-\mathrm{C}-\mathrm{H}$ fashion resulting in a slightly elongated $\mathrm{C} 1-\mathrm{H} 1$ bond distance of $1.11 \AA$ (Fig. 5) compared to the $\mathrm{C}-\mathrm{H}$ distance of $\sim 1.14 \AA$ in $\mathbf{B}-\mathbf{C H}_{\mathbf{4}}$. The calculated Ti-H1 and Ti-C1 distances of 2.26 and $2.85 \AA$ are significantly longer than those found in B- $\mathbf{C H}_{4}\left(d_{\mathrm{Rh}-\mathrm{H}}=1.87 \AA\right.$ and $\left.d_{\mathrm{Rh}-\mathrm{C}}=2.38 \AA\right)$. These longer $\mathrm{C}-\mathrm{H}$ bonds are in line with the thermodynamics which suggest that methane is very loosely bound in $\mathbf{A}-\mathbf{C H}_{\mathbf{4}}$. The calculated enthalpy difference of $0.8 \mathrm{kcal} \mathrm{mol}^{-1}$ between the separated products and $\mathbf{A}-\mathbf{C H}_{\mathbf{4}}$ indicates that the methane extrusion step is almost entirely entropy driven ${ }^{24}$ and the upper limit of the corresponding barrier can be estimated to be $3-4 \mathrm{kcal} \mathrm{mol}^{-1}$. Intuitively, the rapid, entropy-assisted loss of methane from $\mathbf{A}-\mathbf{C H}_{\mathbf{4}}$ to yield $\mathbf{A}^{25}$ should prevent the reactivation of the $\mathrm{C}-\mathrm{H}$ bond. At present however, our isotopic labeling and kinetic data cannot distinguish either pathway for exchange.

\section{Conclusions}

In conclusion, two new paradigms involving metal-carbon multiple bonds have been established. First, we demonstrated that a titanium-carbon triple bond is unambiguously involved in the direct activation of methane at room temperature. Second, we showed indirectly that the methyl hydrogens in $\mathbf{4}$ are undergoing slow exchange with the alkylidene hydrogen.

The dehydrogenation of $\mathrm{CH}_{4}$ to methylidene is especially important because it could allow for the conversion of methane to an industrially important reagent such as ethylene, via intermolecular " $\mathrm{CH}_{2}$ " coupling routes. ${ }^{27}$ However, at present, this conversion has been proposed for silica-supported Ta(III) alkane metathesis catalysts or metal clusters. ${ }^{4,7,8}$ The former reaction has been predicted to occur by a series of steps such as $\sigma$-bond metathesis of (surface) $\mathrm{Ta}(\mathrm{H})$ with methane followed by $\alpha$-hydride elimination to yield (surface) $\mathrm{Ta}=\mathrm{CH}_{2}(\mathrm{H}){ }^{26}$ However, our work suggests that $1,2-\mathrm{CH}$ bond addition ${ }^{9-11}$ and tautomerization can also be plausible pathways for the dehydrogenation of methane, forming in the process, a terminal titanium methylidene ${ }^{28}$ reminiscent of Tebbe's reagent, without necessitating a two-electron redox process. ${ }^{29}$ Unfortunately, our labeling and kinetic studies do not provide any evidence for secondary KIE taking place in the exchange process.

The possibility of a $\sigma$-methane complex, $\mathbf{A}-\mathbf{C H}_{\mathbf{4}}$, as an intermediate for exchange cannot be discarded, but such a putative species must be relatively long-lived in order to allow for $\mathrm{H}$ exchange rather than replacement with the medium such as benzene. Previous work in our group has established that $\mathbf{A}$ activates benzene, via formation of an adduct $\mathbf{A}-\mathbf{C}_{6} \mathbf{H}_{6}$, which has a long enough lifetime to allow for the determination of the intramolecular equilibrium $\operatorname{KIE}\left(\mathrm{C}_{6} \mathrm{H}_{6} / 1,3,5-\mathrm{C}_{6} \mathrm{H}_{3} \mathrm{D}_{3}, 1.33(3)\right)$ which is different from the intermolecular $\operatorname{KIE}\left(\mathrm{C}_{6} \mathrm{H}_{6} / \mathrm{C}_{6} \mathrm{D}_{6}, 1.03\right.$ (7)). ${ }^{10 a}$ These results suggest that binding of the arene is the slowest step in the $\mathrm{C}-\mathrm{H}$ bond breaking process (but not ratedetermining overall).

We estimate the rate of exchange in $\mathbf{4}$ to be slower than, but comparable to the elimination of methane $\left(10^{-6} \mathrm{~s}^{-1}\right.$ at $\left.60^{\circ} \mathrm{C}\right)$. The reactivity of $\mathbf{4}$ with $\mathrm{Al}\left(\mathrm{CH}_{3}\right)_{3}$ and $\mathrm{NC}^{\prime} \mathrm{Bu}$ suggests this species to be an alkylidyne synthon, $\mathbf{A}$. Unfortunately, the latter process is encumbered by the irreversible $\alpha$-hydrogen abstraction to eliminate methane. Current efforts are being devoted to the other volatile paraffins since $\beta$-hydrogens might play an essential role.

\section{Acknowledgements}

Financial support of this research was provided by the National Science Foundation (CHE-0848248, CHE-0645381). D.J.M. acknowledges support from the Alexander von Humboldt Stiftung for a Friedrich Bessel Research Award and M.H.B. thanks the Research Corporation for funding. D.B. and D.J.M. thank Prof. John E. Bercaw and Dr Edward Weintrob for insightful discussions and for allowing usage of their high-pressure setup. Dr Jonathan A. Karty is also thanked for assistance with analytical methods. M.G.C. thanks CONACYT for a postdoctoral fellowship.

\section{Notes and references}

1 For some comprehensive reviews. (a) D. Balcells, E. Clot and O. Eisenstein, Chem. Rev., 2010, 110, 749; (b) A. E. Shilov and G. B. Shul'pin, Chem. Rev., 1997, 97, 2879; (c) H. Arakawa, et al., Chem. Rev., 2001, 101, 953; (d) B. G. Hashiguchi, C. H. Hoevelmann, S. M. Bischof, K. S. Lokare, C. H. Leung, and R. A. Periana, Methane to Methanol Conversion. Energy Production and Storage: Inorganic Chemical Strategies for a Warming World, Ed. Robert H. Crabtree, Wiley: New York, 2010, 101.

2 C. Copéret, Chem. Rev., 2010, 110, 656.

3 For some selected examples. (a) E. Le Roux, M. Taoufik, C. Coperet, A. de Mallmann, J. Thivolle-Cazat, J.-M. Basset, B. M. Maunders and G. J. Sunley, Angew. Chem., Int. Ed., 2005, 44, 6755; (b) D. Soulivong, C. Copéret, J. Thivolle-Cazat, J.-M. Basset, B. M. Maunders, R. B. A. Pardy and D. J. Sunley, Angew. Chem., Int. Ed., 2004, 43, 5366; (c) M. Taoufik, E. Le Roux, J. ThivolleCazat and J.-M. Basset, Angew. Chem., Int. Ed., 2007, 46, 7202; (d) E. Le Roux, M. Chabanas, A. Baudouin, A. de Mallmann, C. Copéret, E. Alessandra Quadrelli, J. Thivolle-Cazat, J.-M. Basset, W. Lukens, A. Lesage, L. Emsley and G. J. Sunley, J. Am. Chem. Soc., 2004, 126, 13391; (e) V. Vidal, A. Théolier, J. Thivolle-Cazat and J.-M. Basset, Science, 1997, 276, 99. 
4 C. Thieuleux, A. Maraval, L. Veyre, C. Copéret, D. Soulivong, J.-M. Basset and G. J. Sunley, Angew. Chem., Int. Ed., 2004, 43, 5366.

5 (a) A. Salameh, J. Joubert, A. Baudouin, W. Lukens, F. Delbecq, P. Sautet, J.-M. Basset and C. Copéret, Angew. Chem., Int. Ed., 2007, 46, 3870; (b) A. Salameh, J. Joubert, A. Baudouin, J.-M. Basset and C. Copéret, Angew. Chem., Int. Ed., 2008, 47, 2117.

6 (a) A. S. Goldman, A. H. Roy, Z. Huang, R. Ahuja, W. Schinski and M. Brookhart, Science, 2006, 312, 257; (b) B. C. Bailey, R. R. Schrock, S. Kundu, A. S. Goldman, Z. Huang and M. Brookhart, Organometallics, 2009, 28, 355.

7 Non-oxidative coupling of methane to ethane (and some ethylene) has been observed in tantalum-hydride supported on silica. (a) D. Soulivong, S. Norsic, M. Taoufik, C. Copéret, J. Thivolle-Cazat, S. Sudhakar Chakka and J.-M. Basset, J. Am. Chem. Soc., 2008, 130, 5044. Methane activation and functionalization with an olefin have been reported; $(b)$ A. D. Sadow and T. D. Tilley, J. Am. Chem. Soc., 2003, 125, 7971; (c) A. D. Sadow and T. D. Tilley, Angew. Chem., Int. Ed., 2003, 42, 803.

8 (a) M. V. Tsodikov, Y. V. Slivinskii, V. P. Mordovin, O. V. Bukhtenko, G. Colón, M. C. Hidalgo and J. A. Navío, Chem. Commun., 1999, 943; (b) S. M. Lang, T. M. Bernhardt, R. N. Barnett and U. Landman, Angew. Chem. Int. Ed., 2010, 49, 980.

9 (a) A. P. Duncan and R. G. Bergman, Chem. Rev., 2002, 2, 431; (b) H. van der Heijden and B. Hessen, J. Chem. Soc., Chem. Commun., 1995, 145; (c) C. B. Pamplin and P. Legzdins, Acc. Chem. Res., 2003, 36, 223; (d) M. P. Coles, V. C. Gibson, W. Clegg, M. R. J. Elsegood and P. A. Porrelli, Chem. Commun., 1996, 1963; (e) J. Cheon, D. M. Rogers and G. S. Girolami, J. Am. Chem. Soc., 1997, 119, 6804; (f) E. Tran and P. Legzdins, J. Am. Chem. Soc., 1997, 119, 5071; (g) C. S. Adams, P. Legzdins and W. S. McNeil, Organometallics, 2001, 20, 4939; $(h)$ C. S. Adams, P. Legzdins and E. Tran, Organometallics, 2002, 21, 1474; (i) K. Wada, C. B. Pamplin and P. Legzdins, J. Am. Chem. Soc., 2002, 124, 9680; (j) K. Wada, C. B. Pamplin, P. Legzdins, B. O. Patrick, I. Tsyba and R. Bau, J. Am. Chem. Soc., 2003, 125, 7035; (k) J. Y. K. Tsang, M. S. A. Buschhaus, P. Legzdins and B. O. Patrick, Organometallics, 2006, 25, 4215; (l) C. S. Adams, P. Legzdins and E. Tran, J. Am. Chem. Soc., 2001, 123, 612; (m) J. Y. K. Tsang, M. S. A. Buschaus, P. Legzdins and B. O. Patrick, Organometallics, 2006, 25, 5188; (n) J. G. Andino, U. J. Kilgore, A. Ozarowski, J. Krzystek, J. Telser, M. Pink, M.-H. Baik and D. J. Mindiola, Chem. Sci. 2010, 1, 351.

10 (a) B. C. Bailey, H. Fan, E. W. Baum, J. C. Huffman, M.-H. Baik and D. J. Mindiola, J. Am. Chem. Soc., 2005, 127, 16016; (b) B. Bailey, H. Fan, J. C. Huffman, M.-H. Baik and D. J. Mindiola, J. Am. Chem. Soc., 2007, 129, 8781; (c) A. R. Fout, J. Scott, D. L. Miller, B. C. Bailey, J. C. Huffman, M. Pink and D. J. Mindiola, Organometallics, 2009, 28, 331.

11 (a) C. C. Cummins, S. M. Baxter and P. T. Wolczanski, J. Am. Chem. Soc., 1988, 110, 8731; (b) C. C. Cummins, C. P. Schaller, G. D. Van Duyne, P. T. Wolczanski, A. W. E. Chan and R. Hoffmann, J. Am. Chem. Soc., 1991, 113, 2985; (c) C. P. Schaller and P. T. Wolczanski, Inorg. Chem., 1993, 32, 131; (d) C. P. Schaller, C. C. Cummins and P. T. Wolczanski, J. Am. Chem. Soc., 1996, 118, 591; (e) D. F. Schafer II and P. T. Wolczanski, J. Am. Chem. Soc., 1998, 120, 4881; (f) J. de With and A. D. Horton, Angew. Chem., Int. Ed. Engl., 1993, 32, 903.
12 B. C. Bailey, Synthesis, Characterization, and reactivity of TitaniumLigandMultiply Bonded Complexes Supported by Sterically Encumbering $\beta$-Diketiminate and PNP Pincer-Type Ligands. Ph.D. Thesis, Department of Chemistry, Indiana University, Bloomington, Indiana, USA, 2006.

13 See supporting information for experimental details $\uparrow$.

14 J. Y. K. Tsang, M. S. A. Buschhaus, P. M. Graham, C. J. Semiao, S. P. Semproni, S. J. Kim and P. Legzdins, J. Am. Chem. Soc., 2008, 130, 3652.

15 A. R. Fout, D. Buck, B. C. Bailey, H. Fan, J. C. Huffman, M.-H. Baik and D. J. Mindiola, Organometallics, 2010, 29, 5409.

16 (a) A. E. Sherry and B. B. Wayland, J. Am. Chem. Soc., 1990, 112, 1259; (b) B. B. Wayland, S. Ba and A. E. Sherry, J. Am. Chem. Soc., 1991, 113, 5305; (c) A. P. Nelson and S. G. DiMagno, J. Am. Chem. Soc., 2000, 122, 8569; (d) B. A. Arndtsen and R. G. Bergman, Science, 1995, 270, 1970; (e) A. Caballero, E. Despagnet-Ayoub, M. Mar Díaz-Requejo, A. Díaz-Rodríguez, M. E. González-Núñez, R. Mello, B. K. Muñoz, W.-S. Ojo, G. Asensio, M. Etienne and P. J. Pérez, Science, 2011, 332, 835.

17 J. H. Oskam and R. R. Schrock, J. Am. Chem. Soc., 1992, 114, 7588.

18 B. C. Bailey, A. R. Fout, H. Fan, J. Tomaszewski, J. C. Huffman and D. J. Mindiola, Angew. Chem., Int. Ed., 2007, 46, 8246.

19 B. C. Bailey, A. R. Fout, H. Fan, J. C. Huffman, J. B. Gary, M. J. A. Johnson and D. J. Mindiola, J. Am. Chem. Soc., 2007, 129, 2234.

$20 \mathrm{H}$-migration in bimetallic $\mu_{2}$-methyl and $\mu_{2}$-methylidene has been observed previously in a heterobimetallic Ti/Rh system.J. W. Park, P. B. Mackenzie, W. P. Schaefer and R. H. Grubbs, J. Am. Chem. Soc., 1986, 108, 6402 .

21 R. R. Schrock, A. J. Jiang, S. C. Marinescu, J. H. Simpson and P. Müller, Organometallics, 2010, 29, 5241.

22 (a) E. Clot and O. Eisenstein, Structure and Bonding, 2004, 113, 1; (b) M. Brookhart, M. L. H. Green and G. Parkin, Proc. Natl. Acad. Sci. U. S. A., 2007, 104, 6908.

$23 \mathrm{~W}$. H. Bernskoetter, C. K. Schauer, K. I. Goldberg and M. Brookhart, Science, 2009, 326, 553.

24 T. R. Cundari, Organometallics, 1993, 12, 1998.

25 Locating the transition state for loss of methane is, unfortunately, impossible with standard quantum mechanical methods, because entropy plays a pivotal and non-trivial role in determining this transition-state energy.

26 S. Arndt, R. R. Schrock and P. Müller, Organometallics, 2007, 26, 1279.

27 For some seminal examples. (a) N. J. Cooper and M. L. H. Green, $J$. Chem. Soc., Dalton Trans., 1979, 1121; (b) J. D. Fellmann, H. W. Turner and R. R. Schrock, J. Am. Chem. Soc., 1980, 102, 6608; (c) A. Van Asselt, B. J. Burger, V. C. Gibson and J. E. Bercaw, J. Am. Chem. Soc., 1986, 108, 5347.

28 Terminal titanium methylidenes have not been isolated but similar species have been spectroscopically observed in the reactions of laser-ablated $\mathrm{Ti}$ atoms and $\mathrm{CH}_{4}$ in argon at $8 \mathrm{~K}$. L. Andrews, H.-G. Cho and X. Wang, Inorg. Chem., 2005, 44, 4834.

29 (a) P. B. Mackenzie, R. J. Coots and R. H. Grubbs, Organometallics, 1989, 8, 8; (b) J. D. Meinhart, E. V. Anslyn and R. H. Grubbs, Organometallics, 1989, 8, 583. 